\title{
Espaço Semente: democratização de práticas artísticas comunitárias em uma periferia de Brasília - DF
}

Valdeci Moreira de Souza ${ }^{1}$

Submetido em: 20/04/2020

Aprovado em: 20 05//2020

DOI: $10.5965 / 2358092521232020235$

\footnotetext{
1 Doutorando em Teatro pela Universidade do Estado de Santa Catarina (UDESC). Professor da Secretaria de Estado de Educação do Distrito Federal, ator e diretor teatral. E-mail: valdecimsouza@gmail.com
} 


\section{RESUMO}

Este artigo visa discutir a variedade de práticas comunitárias em artes, em especial as focadas no teatro, utilizando das experiências do Espaço Semente, local de exercício artístico na periferia da capital do Brasil. Para isso, foram levantadas questões sobre Comunidade, bem como suas práticas, enquanto termos capazes de abarcar a complexidade de uma prática que se pretenda abrangente como a do Espaço Semente. Diante da trajetória apresentada, esse artigo sugere ação cultural e ação artística como categorias de análise que acrescentem à discussão, com foco no seu potencial de inclusão e democratização dos meios de produção de arte e cultura.

Palavras-chave: comunidade, Espaço Semente, ação cultural e artística.

\section{ABSTRACT}

This paper discusses the variety of artistic practices in communities, especially those focused on theater, using the experiences of Espaço Semente, a place on the periphery of the Brazilian capital, as the starting point. For that purpose, we question how much the term Community, as well as its practices, are capable of compassing the complexity of what Espaço Semente has been doing in its context, as a practice that is intended to be democratic. Given Semente's trajectory and its potential for inclusion and democratization of art's means of production, this article suggests Cultural action and Artistic action as useful analytic categories in this discussion.

Keywords: community, Espaço Semente, cultural and artistic action. 


\section{INTRODUÇÃO}

O Teatro na contemporaneidade tem se difundido a diversos contextos e adotado diversas formas de expressão, as quais revelam compreensões teóricas específicas de seu papel e seus objetivos bem como modos diferentes de colocá-los em prática. De forma que cada vez mais há uma expansão de práticas teatrais diversas para fora dos espaços tradicionais do teatro, ocupando contextos e locais variados com uma perspectiva de que o teatro pode ser acessado por todos os indivíduos e pode exercer um papel pedagógico. A grande variedade e complexidade de práticas que vêm surgindo, porém, carrega consigo conceitos e termos que se relacionam e se sobrepõem, sendo, por muitas vezes, conflitantes.

Esse artigo pretende lançar o olhar sobre uma dessas práticas de expansão do teatro para fora dos espaços tradicionais a partir das experiências da Semente Cia de Teatro e do Espaço Semente na comunidade da cidade do Gama, região periférica de Brasília - DF. O Semente, como chamamos, vem se mostrando um espaço de encontro e do exercício de uma arte feita por e para pessoas periféricas, com o objetivo de popularizar o teatro e proporcionar maior acesso à cultura de um modo geral. Para isso serão tensionados os conceitos de Comunidade, Teatro em Comunidades e Ação Cultural e Artística.

O que é uma comunidade? Quais as possibilidades que nela se apresentam para pensar e praticar a arte? Essas são apenas algumas das questões que esse texto pretende levantar sem a pretensão de esgotar as reflexões desse campo rico e variado, mas sim discutindo a proposta trazida pelo Espaço Semente.

\section{HISTÓRIA E CONTEXTO DO ESPAÇO SE- MENTE}

O Espaço Semente e a Semente Companhia de Teatro foram fundadas oficialmente em 20 de junho de 2007, na cidade do Gama. O Gama corresponde a Região Administrativa II do 
Distrito Federal (RA II), tendo uma população de aproximadamente 132.000 habitantes, de acordo com a Companhia de Planejamento do Distrito Federal (CODEPLAN, 2018). A cidade está a $35 \mathrm{~km}$ de Brasília, e quando comparada com a capital mostra índices inferiores de renda, escolarização, infraestrutura e acesso a arte e cultura.

A maioria dos espaços de cultura do DF estão concentrados no centro. Dos 95 espaços de teatro, companhias ou outros locais relacionados a teatro catalogados pela Secretária de Estado de Cultura e Economia Criativa do Distrito Federal no Mapa das Nuvens (GDF, s.d.), 41 estão na área central do Plano Piloto e apenas 6 no Gama. A cidade tem apenas uma biblioteca pública e nenhuma sala de cinema. Na verdade, a única que tinha, o Cine Itapoã, segundo cinema a funcionar no DF, está fechado e abandonado desde 2005 pela administração pública. Como aponta Camelo (2011), a maior fonte de lazer do Gama talvez seja o futebol, a cidade conta com um estádio onde acontecem jogos nacionais e regionais, o Estádio Walmir Campelo Bezerra, ou Bezerrão.

Há, porém, alguns grupos de teatro na cidade que funcionam, assim como o Semente, de forma independente na maioria das vezes, ou com financiamento governamental esporádico pelos editais de fomento cultural, como o $\mathrm{FAC}^{2}$ ou ainda Emendas parlamentares. Além da Semente Cia de Teatro, realizam suas atividades no Gama a Cia Lábios da Lua e a Bagagem Cia de Bonecos por exemplo, porém a atividade e recepção do público tem sido escassa.

O Gama se vê marginalizada e dependente economicamente da Região Administrativa do Plano Piloto. A falta de acessibilidade aos locais de desenvolvimento de atividades econômicas, educacionais, políticas e principalmente culturais atinge a comunidade não apenas do Gama, mas das demais periferias relacionadas à capital. Para além da questão da inacessibilidade dos preços, a segregação dos espaços culturais acontece através da 
centralização das atividades artísticas em locais de difícil acesso às periferias, como o Centro Cultural Banco do Brasil (CCBB) ${ }^{3}$, juntamente à falta de senso de pertencimento da periferia a esses locais que são muitas vezes ocupados por uma classe artística que pouco se incomoda com as necessidades culturais periféricas.

A produção periférica que ocorre no Gama se encontra invisibilizada em grande parte e não recebe o apoio financeiro e social necessários para fortalecer a cena cultural local. E é nesse contexto que surge o Espaço Semente em 2007, ainda como uma ideia sem muitos contornos, e sem fonte de subsídios financeiros para além de seus próprios membros, mas com o objetivo de trazer e fazer cultura e arte de qualidade junto à comunidade do Gama. Como obstáculos se apresentavam o próprio cenário cultural da cidade, pouco movimentado, e as dificuldades (também financeiras) que advinham de oferecer teatro de graça para pessoas de várias idades, origens, gêneros, condições socioeconômicas, conflitos pessoais e backgrounds educacionais. A primeira ação foi estabelecer uma biblioteca comunitária e colaborativa aberta à população. Nela, qualquer pessoa poderia pegar um livro emprestado sem custo, simplesmente com o compromisso de que o leria, emprestaria para uma outra pessoa em seguida ou o devolveria ao acervo.

Depois, o Espaço Semente abriu o primeiro processo de oficina de iniciação teatral para a comunidade, que resultou no espetáculo Morte e Vida Severina, que estreou ainda em 2009. Os dois espetáculos seguintes, Doces Lembranças de Nós Mesmos (2011) e Infinito Vazio (2013) também foram montados a partir de processos de oficina. As oficinas gratuitas são iniciativas já tradicionais do Espaço Semente, realizadas quase anualmente, para turmas de aproximadamente 60 pessoas, a partir dos 15 anos. Ao final da oficina, os alunos geralmente apresentam um espetáculo que comprova a apreensão da linguagem teatral e o

3 Espaço cultural do Banco do Brasil em Brasília, localizado no Setor de Clubes da Asa Sul, está a aproximadamente $40 \mathrm{~km}$ do Gama. Atualmente não conta com nenhuma linha de transporte público que saia diretamente de qualquer RA, para além da Rodoviária do Plano Piloto, dificultando o acesso a quem não tem carro, por exemplo. 
preparo dado durante os vários meses de exercícios, estudos e experimentação.

Nessa época, entre uma e outra montagem, sempre havia leituras dramáticas, shows e outras atividades culturais, realizadas num pequeno subsolo, que era dividido com a loja de informática que eu mantinha na época, mediante o pagamento de um aluguel. Mas, com o passar do tempo e a crescente quantidade de eventos realizados no espaço, a Administração Regional do Gama concedeu, em novembro de 2013, a cessão de uso de um local público abandonado há 16 anos, onde funcionava anteriormente a Associação dos Artesãos do Gama, em reconhecimento às contribuições do Espaço Semente à comunidade.

O local, porém, ainda não poderia suportar a sede do Semente, tendo em vista seu estado extremamente degradado e servia como ponto de tráfico de drogas, prostituição e abrigo para pessoas em situação de rua. Foi a partir de uma extensa reforma, custeada principalmente por mim, na figura do diretor, e não pela Administração da cidade, e feita na maior parte pelos próprios membros da Cia, que o espaço foi se tornando apropriado para as atividades artísticas.

Nesse local já realizamos diversos trabalhos, entre eles espetáculos teatrais, como Miguilim Inacabado (2015), Faça-se Luz (2016), Macunaíma (2017), Ator (2019), Um Sopro de Vida (2019) e Alvo (2020). Todos estes surgiram a partir de oficinas de iniciação teatral, que foram aos poucos deixando de ser oficinas e se transformando em processos de construção coletiva, em que todos participavam de forma ativa, engajada e múltipla. Aos participantes é dada a oportunidade de experimentar as suas potencialidades, desafiar as suas habilidades e se construir enquanto um sujeito dinâmico, que pode, se quiser, transitar ora como ator ou atriz, ora como dramaturgo ou músico em um processo.

A Cia. tem realizado também leituras dramáticas espetacularizadas. O objetivo é explorar e compreender o texto lido, fomentando a discussão com base no seu conteúdo e sua construção, na vida e na obra do autor, no gênero a qual pertence e no tema, dando oportunidade ao ator e atriz iniciantes de experimentar o palco de um modo mais descontraído e aberto 
com o público. Além delas, já houve festivais de teatro e cinema, exposições de artes visuais e fotografia, e saraus, alguns com fomento da Secretaria de Cultura e Economia Criativa do DF4, mas a maioria das ações realizadas pelo Semente são feitas de forma independente.

O Espaço Semente se relaciona com diversos artistas da cidade, e, se tratando de promover a cultura, sempre está à disposição de contribuir para o desenvolvimento dos artistas locais e para o acesso da população a eventos culturais, tanto de música, teatro, poesia, dança e outros. Até hoje, já passaram mais de 13 mil pessoas pelo Espaço Semente entre oficinas, espetáculos e eventos em geral, porém trabalhamos para que esse número cresça ainda mais.

Como parte disso, o Espaço Semente também incentiva todas as pessoas a procurar se desenvolver e se especializar, tendo, nos últimos anos, visto vários de seus membros sendo aprovados na Universidade de Brasília, por exemplo, em cursos como Artes Cênicas, Letras, Teoria Crítica e História da Arte, Direito, Psicologia, etc. Além disso, constantemente oferecemos assistência para aquelas pessoas que precisam passar na Prova de Habilidades Específicas de Artes Cênicas para entrar nesse curso na UnB.

O Espaço Semente é, atualmente, estruturado com base nas metodologias de teatro em comunidades, nele acontecem as ações culturais e artísticas propostas pela Semente Cia de Teatro ou por terceiros convidados. Para isso se organizam os diretores, atores e profissionais capacitados com conhecimentos técnicos na área teatral e de pesquisa em linguagens cênicas em sua organização. cênica. Hoje, o Semente, Espaço e Cia, tem sua metodologia de atuação estudada em duas dissertações de mestrado pela Universidade de Brasília ${ }^{5}$, uma delas ainda em

4 Como o Festival da Semente Cia de Teatro e convidados em 2016, por exemplo, um dos maiores eventos realizados pelo Espaço Semente e que contou com financiamento estatal. 5 SOUZA, Valdeci M. Espaço Semente: $\mathbf{O}$ teatro comunitário como agente transformador na periferia. Dissertação (Mestrado em Teatro) Universidade de Brasília, Brasília, 2018. SILVA, Ricardo C. G. A poética da cena como instrumento de formação estética e política dos jovens periféricos, como prática de liberdade. Dissertação (Mestrado profissional 
construção.

\section{COMUNIDADES E SUAS PRÁTICAS}

Pode-se considerar a comunidade como o resultado de uma interação entre pessoas, que pode surgir por motivos diversos e em sua ausência se desfaz, sendo, portanto, inexistente por si só. Como fenômeno complexo, desafia tentativas de delimitá-la enquanto um conceito sólido, mantendo-as no campo da abstração. Paula e Balby (2018) nos lembram que enquanto objeto de interações, a comunidade "trata-se sempre de um objeto em vias de se perder, sobre o qual nunca se chega a ter um domínio." (PAULA; BALBY, 2018, p. 108) e que surge no espaço do "fora de si" e entre os indivíduos.

É, portanto, necessário ressaltar que comunidade não é um fenômeno da ordem da uniformização ou da homogeneidade. Nesse espaço de interação que aqui se chama comunidade é que segundo os autores citados as diferenças mais radicais entre os indivíduos se mostram e se projetam do privado para o público. Para ser uma comunidade é necessário que as subjetividades possam se expressar e se colocar em sua forma de pensar, ser e agir, mas ainda sim partilhando de um tempo-espaço e fazendo parte de um todo para determinados fins.

Marcia Pompeo Nogueira ${ }^{6}$ (2018), sugere a conceituação de Anthony Cohen como uma perspectiva útil para se pensar comunidade e enquadrar as suas práticas teatrais. Para o dito autor, a comunidade é uma instância de negociação e construção de sentidos que media a relação do indivíduo com a sociedade e com o mundo. Para ele, a comunidade é uma entidade onde as pessoas adquirem suas experiências mais fundamentais e substanciais da vida social, pois é maior e mais ampla que as relações de parentesco, mas mais próxima e imediata do que

em Artes) Orientação de Rafael L. Villas Boas. - Universidade de Brasília. Início em 2018.

6 Marcia Pompeo Nogueira foi professora da Universidade do Estado de Santa Catarina por 29 anos, lecionando no Programa de Pós-graduação em Teatro. É uma referência do estudo de Teatro em Comunidades no Brasil e no exterior. Infelizmente faleceu em agosto de 2019. 
acreditamos ser a sociedade (COHEN, 2013).

Nos espaços da comunidade, os sentidos não são homogêneos e únicos para todos, mas o que é compartilhado são os símbolos que os carregam (NOGUEIRA, 2018). Assim, mesmo pessoas com visões opostas podem se utilizar deles para se comunicar e se reconhecer entre si, aderindo a ele por diferentes razões, e também mudando sua compreensão sobre ele, isto é, o sentido que esse símbolo carrega. Para Cohen, a comunidade é uma instância de dimensão também simbólica, em que os símbolos se constroem e permitem a construção de sentidos entre as pessoas de uma comunidade e para fora desta (COHEN, 2013).

A discussão desse conceito pode se revelar bem mais complexa, como nos lembra Coradi ${ }^{7}$, sendo sua definição difícil e com pouco consenso. Proximidade geográfica, interação mútua, confluência de interesses, compartilhamento de símbolos e identidade: o termo comunidade "é usado para referir-se aos mais diferentes tipos de agrupamentos como uma espécie de termo coringa. Uma mesma coletividade poderia, sob pontos de vista diferentes, ora ser considerada uma comunidade, ora não" (2017, p. 102). Porém, ainda vale levantar o que outros autores, em uma perspectiva um pouco mais prática, sugerem, pois se tem em vista relacionar "comunidade" com as práticas artísticas que nela podem acontecer.

Nogueira (2007), propõe duas definições principais que podem ser usadas para se pensar no Teatro em Comunidades, que seriam a "comunidade local" e a "comunidade de interesse", conceitos apresentados por Baz Kershaw.

'Comunidade de local' é criada por uma rede de relacionamentos formados por interações face a face, numa área delimitada geograficamente. 'Comunidade de interesse', como a frase sugere, é formada por uma rede de associações que são predominantemente caracterizadas por seu comprometimento em relação

7 Mestre em Artes Cênicas pela Escola de Comunicações e Artes da Universidade de São Paulo (ECA/USP), com a tese Teatro e Comunidade: uma travessia em campo emaranhado (2017). 
a um interesse comum. Quer dizer que estas comunidades podem não estar delimitadas por uma área geográfica particular. Quer dizer também que comunidades de interesse tendem a ser explícitas ideologicamente, de forma a que mesmo se seus membros venham de áreas geográficas diferentes, eles podem de forma relativamente fácil reconhecer sua identidade comum (KERSHAW, 1992. p. 31)

Assim, as comunidades poderiam ser definidas ora como um agrupamento de pessoas delimitado geograficamente ora por pessoas que se reúnam em torno de um interesse comum, de modo simplificado. Mas o que se pode dizer das iniciativas de trabalho com arte em ditas comunidades?

No caso brasileiro, a prática de teatro vem se tornando mais presente em espaços marginalizados de nossa sociedade. Como afirma Telles 8 , o teatro "vem ampliando seus espaços de atuação a partir da realização de projetos onde artistas, universidades, governo e ONGs tornam-se parceiros em ações por todo o país." (2003, p. 66). Dentre essas práticas, os termos mais abrangentes e os mais utilizados tendem a ser o Teatro aplicado, ou applied theatre na literatura internacional e o Teatro Comunitário, defendido por autores brasileiros dos quais se destaca Márcia Pompeo Nogueira.

De origem inglesa, o termo Teatro Comunitário, enquanto um amplo espectro de práticas artísticas de contato com a comunidade, têm uma grande variedade de nomenclaturas, métodos e formas, sendo um fenômeno que se manifesta de acordo com seu local, época, finalidade da ação artística e estética. Como ressaltam Nogueira e Rosa, o teatro comunitário pode aparecer em seis modalidades distintas, a depender das instituições a que sua prática se vincula, podendo ser movimentos sociais, OSC (ou ONGs), práticas religiosas, instituições educativas, políticas públicas e grupos de teatro (2006, p. 40).

8 Narciso Telles é Pós-doutor em Teatro pela UDESC e pela Universidade Autônoma Metropolitana do México (UAM), professor do Curso de Teatro do Programa de Pós-Graduação em Artes Cênicas e Mestrado Profissional em Artes na Universidade Federal de Uberlândia (UFU) e colaborador no Programa de Pós-Graduação em Educação/UFU e no PPGAC/UFMA. 
Nogueira ainda identifica três diferentes modelos de atuação nas comunidades, os quais se caracterizam pelo maior ou menor grau de protagonismo das comunidades nos processos que as têm como foco (NOGUEIRA, 2017). São elas: Teatro nas comunidades, Teatro com comunidades e Teatro para comunidades. O primeiro seria um modo de levar o teatro a comunidades periféricas feito por artistas que a desconhecem, "um teatro de cima pra baixo, um teatro de mensagem" (2017, p. 2); o segundo seria mais participativo, com as linguagens e os conteúdos da comunidade trazidos para a ação cênica e incorporados no trabalho; no último modelo, as próprias pessoas da comunidade são incluídas no processo, dando a elas os meios de produção teatral. E como ressalta a autora, para uma prática teatral ser considerada teatro em comunidades "não basta se apresentar como teatro na comunidade. É preciso que seu conteúdo e/ou forma dialoguem com a comunidade." (2017, p. 14). Isto é, a localidade onde o teatro é desenvolvido não determina, por si só, o tipo de teatro realizado nem seus objetivos, pois no teatro em comunidades, a relação com esta é o foco e o eixo organizador de suas ações.

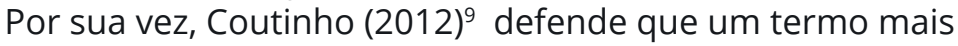
apropriado e abrangente seria "teatro aplicado", ou applied theatre, pois este comportaria diversas práticas teatrais que fogem daquilo considerado teatro tradicional e dos espaços tradicionais ou escolares: "o conceito comum a todas essas práticas [...] é o que garante às pessoas, ou às comunidades, a sua participação, colocando em primeiro plano o envolvimento delas no processo criativo" (COUTINHO, 2012, p. 96). Práticas ou modalidades teatrais das mais diversas estariam sendo agrupadas de acordo com certos aspectos e características comuns:

Todas acontecem longe do âmbito das salas tradicionais de espetáculo, além do território do mainstream, ou do teatro comer-

9 Marina Henriques Coutinho é professora do Programa de Pós-Graduação em Ensino das Artes Cênicas (PPGEAC) e do Programa de Pós-Graduação em Artes Cênicas (PPGAC) da Universidade Federal do Estado do Rio de Janeiro (UNIRIO). Sua tese de doutorado, A favela como palco e personagem (2012), é uma das bases para essa pesquisa. 
cial; são iniciativas que levam o teatro a determinadas comunidades, que envolvam a participação de pessoas comuns, suas histórias, lugares, desejos, prioridades e que são motivadas pelo desejo político de transformar, por meio do teatro, realidades individuais ou coletivas. (COUTINHO, 2012, p. 89)

Apesar dessa indeterminação de um nome que advém tantas práticas diferentes, alguns autores, como Adame (2017), ressaltam que a nomenclatura é um elemento que pode ser relegado ao segundo plano, na medida em que o processo esteja baseado na interação da arte com a comunidade. Assim, o teatro na comunidade ou o teatro aplicado pode ser representado como uma prática que assume várias nomenclaturas e vários contextos, mas que se caracterizam essencialmente como um exercício artístico comprometido com o impacto e a participação das comunidades em seu próprio meio, em sua própria vida cotidiana. Dependendo de características de cada uma dessas formas de se fazer teatro em comunidades, estas podem ser mais ou menos implicadas dentro de cada processo, às vezes como foco da ação teatral, outras vezes como quem a põe em prática desde o começo, vide a diferenciação apontada por Nogueira (2017). Para fins deste artigo, como precisar as práticas realizadas pelo Espaço Semente? Para tentar responder a esta questão, ainda é necessário explorar os conceitos de ações culturais e ações artísticas.

\section{AÇÕES CULTURAIS E ARTÍSTICAS}

Para além de estabelecer delimitações entre ação cultural e ação artística também é necessário estabelecer uma relação entre esses conceitos com o trabalho realizado pela Semente Cia de Teatro com sua comunidade. Para começar, vale ressaltar que a separação e definição de tais termos nunca é bastante precisa. Como afirma Maria Lúcia $\operatorname{Pupo}^{10}$ a noção de ação cul- 
tural é às vezes nebulosa, "uma moldura que reúne as mais fecundas formulações de contrapartida observada" (2012, p. 160), visto o contexto cultural em que surgiu e vem sendo utilizada.

Teixeira Coelho ${ }^{11}$ faz, entretanto, a definição de ação cultural mais detalhada em seu Dicionário Crítico de Política Cultural, no qual compreende que uma ação cultural é um "conjunto de procedimentos, envolvendo recursos humanos e materiais, que visam pôr em prática os objetivos de uma determinada política cultural" (1997, p. 31), diferindo-se em quatro tipos de acordo com o nível da produção cultural que visam atingir: produção, a distribuição, a troca e o uso ou consumo. Para o autor, ação cultural é uma ação que visa estabelecer pontes entre as pessoas e o objeto/ obra de expressão cultural ou arte. Isso também significa compreender esse termo "como o processo de criação ou organização das condições necessárias para que as pessoas e grupos inventem seus próprios fins no universo da cultura." (COELHO, 1997, p. 32).

O termo foi bastante difundido em São Paulo, a partir do início dos anos 2000 "em face das propostas de contrapartida social surgidas com o Programa Municipal de Fomento ao Teatro" (DESGRANGES, 2017, p. 219). Uma das modalidades mais oferecidas como contrapartida pelos grupos de teatro da cidade de São Paulo são as oficinas, com o objetivo de trazer benefícios para a população que delas participar, e têm sido responsáveis por interessantes transformações no contexto das artes cênicas da cidade, promovendo renovação teatral e social (PUPO, 2012). O surgimento e desenvolvimento desse modo de atuação têm relação com o deslocamento da atuação dos artistas da prioridade da montagem de espetáculos para outras ações tangentes à vida pública (DESGRANGES, 2017).

agogia, formação, teatro contemporâneo, ação cultural, mediação teatral e dramaturgia. Tem mestrado em Artes pela USP e doutorado em Études Théâtrales pela Université de Paris III (Sorbonne-Nouvelle) (1985).

11 José Teixeira Coelho Netto é professor titular aposentado e Professor Emérito da ECAUSP. Possui graduação em Direito (1971) pela Universidade de Guarulhos, mestrado em Ciências da Comunicação (1976) pela ECA-USP, doutorado em Teoria Literária e Literatura Comparada (1981) pela FFLCH-USP e pós-doutorado pela University of Maryland, EUA (2002) 
Como explica Carasso (2012), a ação cultural passa por uma visão de alargar o campo cultural, possibilitando maior acesso a diferentes modalidades culturais. Isso significa também incentivar iniciativas de difusão de obras, mediação em teatros e museus, e em termos matérias como preços e meios de transporte que permitam maior acessibilidade de diferentes grupos sociais. Percebe-se, então, a sua ligação estreita com a elaboração e a manutenção de políticas públicas do Estado, em maior ou menor cooperação com a classe artística.

Desgranges ${ }^{12}$ afirma em seu livro A Inversão da Olhadela que as ações culturais, assim como as ações artísticas, surgem de uma mudança no modo de se produzir arte e de fazê-la circular. Porém, as últimas tratam-se de práticas coletivas de interação de grupos de teatro com o espaço público e o público, que pode participar de formas diversas, mais direta ou mais indiretamente do processo de criação. (DESGRANGES, 2017).

A distinção entre essas duas práticas pode ser ainda definida por Pupo:

No bojo das ações artísticas o que se salienta é a singularidade da percepção estética presente na experiência sensível, assim como nos riscos que ela necessariamente comporta. Ao fazer arte se constrói a subjetividade, ao mesmo tempo em que simbolicamente se reconstrói um território comum. Nessa ótica seria oportuno distinguir, como faz Teixeira Coelho em A cultura e seu contrário (São Paulo, Iluminuras, 2008), a especificidade de uma ação artística em relação à ação mais amplamente tida como cultural, partindo do princípio de que a arte, em larga medida é a negação da cultura. Seu caráter divergente faz com que ela seja uma exceção em relação às manifestações da cultura, que remetem à regra. (PUPO, 2012, p. 48)

Como explica a autora, a ação artística se difere da ação cultural por não só incidir sobre o acesso da arte e da cultura para a população, como seriam mediações e cursos de teatro, 
mas em articular isso de modo novo, em um processo contrário à "regra" cultural. Dela, também é objetivo dar voz e incluir pessoas que normalmente estariam afastadas da produção da arte e não só de seu consumo, o artista enquanto figura catalisadora, revelaria as "questões vitais que atravessam a sociedade. Mediante as situações desestabilizadoras que constrói, o artista suscita o questionamento daquilo que pode nos parecer evidente" (PUPO, 2012, p. 48). Nesse tipo de prática, que Desgranges (2017) afirma ser formativa, o papel do artista estaria em articular e transformar estados, estimulando os participantes a se engajarem no processo e colocarem-se em um movimento investigativo e ativo.

Em complemento a esse pensamento, Carasso (2012) propõe que ao contrário da ação cultural, a artística compreende movimentação, transformação e renovação de um certo contexto ou pressuposto cultural. As oficinas de teatro trazidas por Pupo (2012) como uma das ações mais frequentes no contexto de São Paulo, seriam somente consideradas ações artísticas se, para além de incentivarem e aumentarem o acesso de populações geralmente delas excluídas, fossem também um espaço de crítica, experimentação e protagonismo.

De um modo geral, pode-se considerar que o Espaço Semente realiza constantemente os dois tipos de ações, às vezes visivelmente definidas, outras vezes de contornos menos visíveis. As ações culturais estão mais focadas na ocupação do espaço físico, tornando o Semente um ponto de encontro entre a arte e a cultura com a população da cidade. Por exemplo, quando são realizados shows, exposições, festivais como a $50^{a}$ edição do Festival de Brasília do Cinema Brasileiro, que ocorreu em 2017 e teve o Espaço Semente como um dos locais de exibição de filmes, o foco é ampliar os tipos de produtos culturais que chegam a comunidade e aproximá-los das pessoas, estabelecendo pontes.

No caso das ações artísticas, o exemplo mais claro são as oficinas de teatro. Mais do que oferecer uma formação básica em interpretação, as oficinas de iniciação teatral visam inaugurar processos de criação coletiva e transformação individual. Os 
espetáculos do Semente, dos quais a maioria começou como oficinas abertas para a comunidade, se baseiam em aproximações e contribuições dos participantes, geralmente envolvendo processos de estudo grupal, individual, sugestões para a direção, para o cenário, para a maquiagem, participação na construção do figurino e dos demais materiais etc.

Um dos pontos principais do trabalho do Semente em suas oficinas e montagens é o uso de obras da literatura brasileira como ponto de partida. Desde o início da Companhia, livros como Morte e Vida e Severina, de João Cabral de Melo Neto, são trazidos para dentro dos processos, discutidos, interpretados, adaptados e recriados de acordo com as nossas necessidades e visões de mundo. A literatura se funde ao teatro nesse contexto tanto para servir de meio para tratar dos problemas de uma realidade periférica, local e específica que enquanto atores e atrizes amadores $^{13}$, habitantes do Gama compartilhamos, quanto para expressar inquietações e questionamentos de outra ordem, tratando dos temas complexos da vida, das dimensões simbólicas e metafóricas que a arte proporciona serem tocadas.

Hoje, grande parte das pessoas envolvidas com o Semente entraram em contato com o teatro pela primeira vez através das oficinas oferecidas para a comunidade de forma gratuita. Uma das características principais dos processos de montagem da Companhia é o trabalho com não-atores, ou seja, com aquelas pessoas que nunca haviam tido contato com o trabalho de atuar em um palco. Sendo assim, construir um espetáculo é também um trabalho de ensino do teatro, suas técnicas, sua história etc. De certa forma, oferecer as oficinas, montar espetáculos e introduzir o participante dentro de um universo das artes é uma atividade de formação de público que visa criar demanda para o cenário cultural da comunidade e instigar a produção de arte pelos próprios participantes. 


\section{PARA UMA ARTE DE E POR TODOS}

Para além de se mostrar a arte, um espetáculo ou o "produto final" de um processo de criação, o objetivo do teatro comunitário e de um fazer teatral engajado é o envolvimento, a mobilização, a transformação que se empreende no caminho, isto é, o processo é o mais importante. Segundo Telles (2003), o trabalho de teatro possibilita a apreensão de aspectos das expressões artísticas sofisticadas da arte "erudita" e a construção ao mesmo tempo de novas formas de representação simbólica que caibam na realidade dessa comunidade.

O fazer do Espaço Semente, ações culturais e artísticas, pretende contribuir para a conquista e a manutenção da cidadania que é alijada dos moradores da periferia pela negligência do Estado. Dessa forma ele passa a ser usado como um instrumento de reflexão e crítica que visa dotar os sujeitos com as armas da própria liberação intelectual. Um dos objetivos do Semente é "despertar um processo de transformação no indivíduo para que ele possa assumir o caráter de sujeito ativo, mais do que um ator que simplesmente emula um texto em seu corpo e voz." (SOUZA, 2018, p. 23). Isso significa possibilitar ao participante conhecimentos e formas de expressão que ajudem a pensar os problemas de sua comunidade, sendo estimulado a aprender e a se aperfeiçoar de forma ativa. No Semente, cada participante é incentivado a pesquisar, a se descobrir, a explorar os seus conhecimentos e as suas potencialidades. Espera-se que ele desenvolva sua autonomia dentro e fora dos palcos.

No processo do espetáculo Macunaíma, que estreou em 2017 no Espaço Semente, isso fica bastante evidente. Fruto de uma oficina iniciada em 2016, e adaptação da obra modernista de Mário de Andrade, o espetáculo aborda a questão da identidade brasileira de forma crítica, cômica e carnavalesca em um palco sem coxias e repleto de frutas tropicais que é muito próximo da plateia, intimista. Para resumir, a história gira em torno do personagem Macunaíma, indígena nascido negro no coração da Amazônia, e sua trajetória da floresta à metrópole de São Paulo do começo do século XXI para recuperar um objeto per- 
dido.

A montagem foi um exercício de reflexão e crítica da realidade brasileira, em uma perspectiva ampla e também local, da comunidade na qual e com a qual o trabalho foi realizado. Macunaíma surgiu depois de vários seminários organizados pelo grupo a fim de pesquisar e estudar o tema que seria analisado, introduzindo e modificando símbolos pertinentes, mitos, expressões da cultura popular, problemas sociais. Além disso, a adaptação tratou de modernizar e ressignificar a narrativa, trazendo elementos que atravessavam a obra e a atualidade dos participantes. Souza afirma que:

[...] a obra proporcionou aos alunos uma nova percepção da facticidade das dificuldades e das belezas do Brasil enquanto nação (ou, ainda, nações) e enquanto Estado, levantando discussões sobre as relações étnico-raciais, de classe, de gênero, sobre o convívio e a preservação da natureza e das populações originais, sobre a cultura popular em decadência [...] e sobre a história política. (SOUZA, 2018, p. 29) $)^{14}$

Diante de tudo, então, o Espaço Semente pode ser considerado um Teatro de Comunidade? Defendo que sim. Primeiramente por ser posto em prática por pessoas da cidade do Gama e da Região do Entorno do Distrito Federal, que geralmente compartilham a vivência de serem pobres, periféricos e/ou negros e de, principalmente, terem pouco ou nenhum acesso ao teatro fora do Espaço Semente. Em segundo lugar, o trabalho realizado ali tem o objetivo de possibilitar a seus participantes a apropriação da linguagem teatral através das oficinas, das montagens de espetáculo etc., possibilitando que elas exercitem suas habilidades e aptidões tanto como atores e atrizes como

14 Vários aspectos da montagem final do espetáculo, como figurino, maquiagem, músicas e cenografia são resultados da contribuição direta e da reflexão individual e grupal sobre os seus próprios entendimentos do que Macunaíma significava em conjunto com a direção também. O Caderno de Encenação de Macunaíma (SOUZA, 2018) traz em detalhes o processo de criação do espetáculo e os seus aspectos pedagógicos e permite observar melhor essa construção coletiva, além das características estéticas, políticas e sociais de Macunaíma e o modo como a montagem tomou com o tempo a sua personalidade. 
técnicos ou outras funções, ou seja, há um foco em sua dimensão pedagógica. Ademais, os trabalhos do Espaço e da Semente Cia de Teatro têm como foco e ponto de partida a realidade de sua comunidade, usando a vivência dos seus participantes como conteúdo ou usando adaptações de obras literárias para investigar e provocar temas.

A comunidade que compõe o Espaço Semente, tanto enquanto membros como enquanto público, caracteriza-se pela marginalização e a forte influência de marcadores sociais e políticos como o racismo, o machismo, o classismo e a violência contra pessoas LGBTQ $+{ }^{15}$. Assim em sua diversidade, a confluência de interesses surge a partir da experiência coletiva afetada por esses marcadores, e através da identidade periférica surge a potência artística necessária para solidificar um fazer teatral comunitário.

\section{CONCLUSÃO}

Estabelecer e analisar os critérios que caracterizam agrupamentos humanos como comunidades "não garante ações pautadas em princípios éticos que consolidem direitos fundamentais para todos" (CORADI, 2017. p. 108), mas é um ponto de partida. A necessidade está em compreender quais possíveis benefícios advêm desta configuração do social, lócus de criação e interação, e como potencializá-los, colocando em perspectiva as iniciativas teatrais dentro destas comunidades e porque elas acontecem.

Os objetivos do Espaço Semente perpassam pela democratização do teatro e pela construção de um fazer artístico transformador, que possibilite aos seus participantes tomar um papel ativo em suas vidas e em sociedade, como cidadãos plenos. Apoiado também nas teorias apresentadas anteriormente, o Se-

15 Sigla que visa abarcar os segmentos da sociedade que se declaram como Lésbicas, Gays, Bissexuais, Travestis e Transexuais, Queer, Intersexuais, Assexuais ou diversas outras identidades e modos de expressão de gênero e sexualidade. A sigla pode ser "resumida" com LGBTQ+. 
mente empreende ações a partir, com e para a sua comunidade, visando conscientizar os indivíduos das opressões que lhes são impostas e, assim, dar possibilidade de contorná-las.

O trabalho do Espaço Semente se concentra em difundir a arte, em especial o teatro, levando-o a um público que antes poderia nunca ter assistido a um espetáculo na vida, talvez muito menos participar de um. Ele parte de uma comunidade local e de interesse, relembrando os conceitos de Kershaw, mas também é responsável por recriar e manter uma comunidade num sentido mais amplo, como um espaço feito das interações entre indivíduos no qual a arte é o instrumento e o catalizador de transformações e reconstruções. 


\section{REFERÊNCIAS}

ADAME, D. Teatro Comunitário do Século XXI para o reencantamento do mundo. In CRUZ, H., BEZELGA, l; RODRIGUES, P. Práticas Artísticas Comunitárias. Porto: PELE, CHAIA - UE/ UID/EAT/FCT, 2017. Disponível em: http://dspace.uevora. pt/rdpc/bitstream/10174/21519/1/Praticas\%20artisticas\%20 Comunitarias\%20E-Book.pdf. Acesso em: 01/04/2020.

CAMELO, E. S. A importância do resgate da memória cultural no processo de ensino-aprendizagem. Artigo (Graduação em Educação Física). Universidade Católica de Brasília, Brasília, 2011. Disponível em: <repositorio.ucb.br:9443/jspui/ handle/123456789/9258. >Acesso em: 16/01/2020.

COHEN, A. P. Symbolic construction of community. Londres, Nova lorque: Routledge, 2013.

CODEPLAN. Governo do Distrito Federal. Pesquisa Distrital por Amostra de Domicílios - Gama. Brasília, Distrito Federal, 2018. Disponível em: < http://www.codeplan.df.gov.br/wp-content/ uploads/2019/03/Gama.pdf> Acesso em: 20/04/2020.

CORADI, T. Z. Teatro e comunidade: uma travessia em campo emaranhado. 2017. Dissertação (Mestrado em Pedagogia do Teatro) - Escola de Comunicações e Artes, Universidade de São Paulo, São Paulo, 2017.

COUTINHO, M. H. A favela como palco e personagem. Rio de Janeiro: FAPERJ, 2012.

DESGRANGES, F. Pedagogia do teatro: provocação e dialogismo. São Paulo: Hucitec, 2006.

DESGRANGES, F. A inversão da olhadela: alterações no ato do espectador teatral. São Paulo: HUCITEC. 2 ed, 2017.

GDF, Secretaria de Estado de Cultura e Economia Criativa do Distrito Federal. Mapa nas Nuvens. Disponível em: <mapa. 
cultura.df.gov.br>. Acesso em: 11/03/2020.

NOGUEIRA, M. P. Teatro e Comunidades: A experiência brasileira. CRUZ, H., BEZELGA, I.; RODRIGUES, P. Práticas Artísticas Comunitárias. Porto: PELE, CHAIA - UE/UID/ EAT/FCT, 2017. Disponível em: http://dspace.uevora.pt/ rdpc/bitstream/10174/21519/1/Praticas\%20artisticas\%20 Comunitarias\%20E-Book.pdf. Acesso em: 01/04/2020.

NOGUEIRA, M. P. A opção pelo teatro em comunidades: alternativas de pesquisa. Urdimento-Revista de Estudos em Artes Cênicas, v. 1, n. 10, p. 127-136, 2018.

NOGUEIRA, M. P; ROSA, M. As ONGs e o teatro em comunidades. DAPesquisa, v. 4, n. 6, p. 40-45, 2018.

NOGUEIRA, Marcia P. Tentando definir o Teatro na Comunidade. In: Reunião Científica De Pesquisa E Pós-Graduação Em Artes Cênicas, 4., 2007. Anais eletrônicos. Belo Horizonte: ABRACE, 2007. Disponível em: http://portalabrace.org/ivreuniao/GTs/ Pedagogia/Tentando\%20definir\%20o\%20Teatro\%20na\%20 Comunidade\%20-\%20Marcia\%20Pompeo\%20Nogueira.pdf. Acesso em: 10/03/2020.

PAULA, J. R.; BALBY, L. F. A comunidade dos que escrevem a comunidade. Alea, Rio de Janeiro, v. 20, n. 2, p. 105-120, Aug. 2018.

PUPO, Maria L. S. B. Quando a cena se desdobra: as contrapartidas sociais. In Teatro e Vida Pública: O fomento e os coletivos teatrais de São Paulo. DESGRANGES, F.; LEPIQUE, M. (orgs). São Paulo: Hucitec Editora, 2012.

SOUZA, V M. Espaço Semente: O teatro comunitário como agente transformador na periferia. Dissertação (Mestrado em Teatro) Universidade de Brasília, Brasília, 2018.

TELLES, Narciso. Teatro Comunitário: Ensino de Teatro e Cidadania. Urdimento - Revista de Estudos em Artes 
Cênicas, [S.I.], v. 1, n. 5, p. 066 - 071, jun. 2017. Disponível em: http://www.revistas.udesc.br/index.php/urdimento/article/ view/1414573101052003066. Acesso em: 01/03/2020. 